\title{
A supressão dos meios de vida dos pescadores profissionais impactados pela Usina Hidrelétrica foz do Chapecó ${ }^{1}$
}

Silvana Winckler*

Arlene Renk**

\section{INTRODUÇÃO}

Os estudos sobre consequências socioambientais da construção de megaprojetos constituem, hoje, considerável parcela da produção científica no campo da Justiça Ambiental, que forma um novo e amplo campo de investigação dedicado aos efeitos perversos das grandes obras de infraestrutura desenvolvidas de norte a sul do Brasil e demais países da América Latina (RIBEIRO, 2008). A rede latino-americana de Justiça Ambiental constitui-se como fórum voltado a analisar a fundo essas obras e a condição dos atingidos desde o ponto de vista do Direito e da Justiça, tendo em vista proporcionar a visibilidade que esse problema merece (BERGER; CARRIZO, 2016; FRASER, 2008; ACSELRAD et al., 2004).

Os conflitos socioambientais não são novidades na história do Brasil. As sucessivas políticas extrativistas levadas a cabo desde a época da colônia deixaram-nos um passivo de exclusão e de destruição que podem ser averiguados nos dias de hoje, sem a necessidade de grandes estudos, tamanha é sua evidência ${ }^{2}$. Anovidade, na atualidade, residena magnitudedosprojetosneodesenvolvimentistas (LAMOSO, 2012) que vêm sendo implementados à revelia da vontade das comunidades direta e indiretamente afetadas. A baixa capacidade de reação e de negociação estão na origem de boa parte dos problemas relativos à falta de reconhecimento das vítimas do desenvolvimento como tais, tanto no decurso do projeto e execução da obra quanto posteriormente, pois seus efeitos se consumam e perduram no tempo.

\footnotetext{
* Doutora em Direito pela Universidade de Barcelona. Professora dos programas de pós-graduação em Ciências Ambientais e Direito da Unochapecó.

** Doutora em Antropologia Social pela UFRJ. Professora dos programas de pós-graduação em Ciências Ambientais e Direito da Unochapecó.
} 
Este texto tem como tema os impactos socioambientais de um megaprojeto do setor hidrelétrico instalado na bacia do rio Uruguai, na divisa dos estados do Rio Grande do Sul e Santa Catarina, que alterou a morfologia de treze municípios diretamente atingidos e de outros indiretamente afetados: a Usina Hidrelétrica Foz do Chapecó. Dentre a população atingida, destacamos os pescadores profissionais da pesca artesanal vinculados à Colônia Z-35, que abrange a região de São Carlos-SC.

Nos primeiros estudos ambientais e no respectivo Relatório de Impactos ao Meio Ambiente (RIMA), a categoria dos pescadores profissionais sequer é mencionada. $\mathrm{O}$ relatório somente faz alusão à existência da pesca amadora (esportiva) no rio Uruguai. Foi a partir da realização da audiência pública, no ano de 2002, que a categoria profissional se mobilizou para sair da invisibilidade a que havia sido relegada. Estudos ambientais complementares foram designados pelo órgão licenciador (IBAMA) e o Plano Básico Ambiental da Foz do Chapecó passou a contemplar o monitoramento da atividade pesqueira e, também, alguns programas compensatórios voltados aos pescadores.

No entanto, a lógica com a qual é pensada a atividade da pesca pelo consórcio empreendedor UHE Foz do Chapecó e por sua sucessora, a Foz do Chapecó Energia, é mercadológica, mensurada por blocos de notas fiscais dos quais nem sempre os pescadores artesanais estão munidos (RENK; AGNOLIN; WINCKLER, 2014).

Além disso, os programas previstos não foram integralmente implementados. O monitoramento da ictiofauna e da qualidade da água acontece regularmente, porém não vem acompanhado de medidas de atenção às famílias que perderam a profissão e o sustento por causa das alterações ambientais desencadeadas. A quantidade e a qualidade do pescado diminuíram sensivelmente, sendo que, atualmente, somente são capturadas espécies de baixo ou nenhum valor de mercado. Na busca por direitos, muitos pescadores recorrem à justiça postulando compensações e indenizações.

De outro lado, há pescadores profissionais que não vêm obtendo, da Previdência Social, o direito ao "seguro defeso", uma vez que a sua condição profissional não é reconhecida pela autarquia federal. É relevante indagar-se acerca dos motivos dessa negativa, porque inviabiliza a permanência na atividade e o exercício da profissão.

Todos esses elementos justificam o presente trabalho, que consiste no estudo das condições de exercício de uma profissão artesanal e tradicional na região afetada pela barragem, atualmente em vias de extinção. Trata-se de uma dimensão não reconhecida de dano ambiental, precisamente aquela que impacta as formas de organização do trabalho e das profissões, as quais são representativas da cultura de uma comunidade.

Trata-se de pesquisa qualitativa (POUPAERT, 2008). Buscou-se inicialmente submergir no campo a fim de encontrar elementos significativos 
para posterior aprofundamento teórico-prático. A população do estudo é formada por pescadores profissionais da pesca artesanal integrantes da Colônia Z-35, na região de São Carlos-SC, que requereram o "seguro defeso" nos últimos três anos e que propuseram ação judicial em face da Foz do Chapecó energia postulando compensações e indenizações por danos decorrentes do empreendimento.

A amostra foi composta por pessoas que estiveram dispostas a conceder entrevistas. Os contatos com os pescadores foram facilitados pelo presidente da Colônia Z-35, que promoveu o agendamento para a realização das entrevistas em consonância com o público delineado. As entrevistas foram realizadas no mês de fevereiro de 2019 na sede da colônia. O número de entrevistas realizadas atendeu ao critério da saturação (respostas repetidas que já não apresentam novidades indicaram o momento de interromper as entrevistas).

As técnicas de pesquisa utilizadas foram o estudo documental e a entrevista mediada por instrumento semiestruturado (questões abertas). Importava, no percurso metodológico, identificar, caracterizar e analisar as estratégias de resistência dos pescadores profissionais ante a ameaça de invisibilidade e de inviabilidade da profissão após a instalação da usina hidrelétrica no leito do rio Uruguai.

\section{GRANDES PROJETOS DE INFRAESTRUTURA E POPULAÇÕES ATINGIDAS}

Os grandes projetos de infraestrutura geram, de um lado, expectativas de desenvolvimento socioeconômico, de oportunidades de trabalho, renda e melhorias de vida, elementos estes que confluem ao bem-estar geral. De outro lado, produzem impactos de igual monta, afetando social, ambiental, cultural e economicamente a vida das pessoas e das comunidades.

O que há de benefícios e o que há de malefícios a computar, nesses contextos, não é tarefa de fácil realização, uma vez que demanda estudos e pesquisas que se estendam no tempo, muito além dos prazos de planejamento e execução das obras. Os efeitos, regra geral, são duradouros e se projetam tanto temporal quanto espacialmente, de modo que as categorias de atingidos podem ampliar-se numérica e qualitativamente nos contextos de conflitos socioambientais.

Svampa (2019) fala do "consenso das commodities", que teria sucedido o consenso de Washington, na ordenação do capitalismo mundial. Neste cenário, a América Latina ocupa um papel de exportadora de matéria prima (minerais, soja, energia, água) aos grandes centros consumidores (os países desenvolvidos: EUA, União Europeia, China). Esse papel periférico na economia mundial é desempenhado mediante a exploração de recursos naturais, de territórios, de comunidades, dando lugar a injustiças e à "ilusão desenvolvimentista". Trata-se do neoextrativismo - uma reedição do extrativismo praticado pelas metrópoles 
em relação às colônias latino-americanas -, categoria que permite análises sobre desigualdades e responsabilidades nas relações entre o norte e o sul global.

A UHE Foz do Chapecó foi construída no rio Uruguai, na divisa dos Estados do Rio Grande do Sul e Santa Catarina. Atualmente é gerenciada pela Foz do Chapecó Energia S.A.. O empreendimento também ficou conhecido como Consórcio Energético Foz do Chapecó, nome com o qual participou do leilão da Agência Nacional de Energia Elétrica (Aneel). A sociedade está formada pelas empresas CPFL Energia (51\%), Eletrobrás Furnas (40\%) e Companhia Estadual de Geração e Transmissão de Energia Elétrica (9\%).

O setor elétrico brasileiro está formado pelo Estado, empreendedores e consultores (Zhouri e Oliveira, 2007). Nos empreendimentos hidrelétricos intervêm duas agências reguladoras: a Agência Nacional de Energia Elétrica (ANEEL), criada pela Lei n. 9.427/1996, e a Agência Nacional de Águas (ANA), criada pela Lei n. 9.984/2000. A Empresa de Pesquisa Energética (EPE) foi criada pela Lei n. 10.847/2004 e tem como função precípua promover estudos de potencial energético, incluindo o inventário de bacias hidrográficas e de viabilidade técnicoeconômica e socioambiental (BERMAN, 2007).

Conforme dados do Balanço Energético Nacional, a energia proveniente de fontes renováveis, no Brasil, corresponde a 43,5\%, sendo 17,5 oriunda da biomassa da cana, 12,6\% hidráulica, $8 \%$ produzida por lenha e carvão vegetal e 5,4 originada de outras fontes. Especificamente no que tange a energia elétrica, a fonte hidráulica responde por 65,2\% (EMPRESA DE PEQUISA ENERGÉTICA, 2018).

A bacia hidrográfica do rio Uruguai é densamente ocupada por população predominantemente rural, de modo que a instalação de barragens implica no alagamento de terras agricultáveis e no deslocamento populacional compulsório. A despeito do princípio legal (Lei n. 9.433/ 1997, Política Nacional de Recursos Hídricos) de uso múltiplo das águas, o setor elétrico vem priorizando a produção energética. De acordo com Bermann (2007, p. 142), as populações ribeirinhas são invariavelmente desconsideradas, imputando-lhes a perda de suas condições de produção e reprodução social:

No relacionamento das empresas do setor elétrico brasileiro com essas populações, prevaleceu a estratégia do "fato consumado" praticamente em todos os empreendimentos. Enquanto a alternativa hidrelétrica era sempre apresentada como uma fonte energética "limpa, renovável e barata", e cada projeto era justificado em nome do interesse público e do progresso, o fato é que as populações ribeirinhas tiveram violentadas as suas bases materiais e culturais de existência.

O autor menciona, além dos deslocamentos forçados, a falta de equivalência das compensações financeiras e dos processos de reassentamento, 
nos casos em que estes foram implementados, todas medidas insuficientes para proporcionar a reprodução das condições de vida da população afetada.

\begin{abstract}
$\mathrm{Na}$ área das barragens, ocorreram diversos problemas de saúde pública, como o aumento de doenças de natureza endêmica, o comprometimento da qualidade da água nos reservatórios, afetando atividades como pesca e agricultura, e problemas de segurança das populações, com o aumento dos riscos de inundação abaixo dos reservatórios, decorrentes de problemas de operação. Ainda, grandes quantidades de terras cultiváveis ficaram submersas e, em muitos casos, a perda da biodiversidade foi irreversível (BERMANN, 2007, p. 142).
\end{abstract}

Pesquisas desenvolvidas em torno da Usina Hidrelétrica (UHE) Foz do Chapecó (BARON, 2012; RENK, AGNOLIN e WINCKLER, 2014; DAL MAGRO et al., 2015) apontam resultados que corroboram o ponto de vista de Bermann.

Baron (2012) evidencia os baixos valores recebidos pelos deslocados a título de compensação e a demora no processo de reassentamento, alternativa mais custosa aos cofres do empreendedor e mais benéfica aos atingidos. $\mathrm{O}$ autor atribui o reduzido número de famílias que optaram pelo reassentamento à incerteza provocada pela demora.

Renk e Winckler (2017) evidenciam os impactos da instalação da barragem na vida das comunidades ribeirinhas: a perda da profissão dos pescadores artesanais, a redução das terras agricultáveis, o desfazimento dos vínculos sociais comunitários, alterações socioambientais que causam sofrimento e desalento às vítimas do desenvolvimento.

Ribeiro (2008) vê o desenvolvimento como um campo de poder formado por redes e instituições no qual atores se articulam em consorciação. Também vê o desenvolvimento como ideologia e utopia, como se verá adiante.

Tomando como referência Richard Adams, Max Weber e Eric Wolf, o Ribeiro diz que poder:

[...] refere-se à capacidade (a) de ser sujeito do seu próprio ambiente, de ser capaz de controlar seu próprio destino, quer dizer, de controlar o curso da ação ou dos eventos que manterão a vida como está ou a modificarão; ou (b) de impedir as pessoas de se tornarem atores "empoderados" (RIBEIRO, 2008, p. 110).

A instalação de uma megaobra envolve, portanto, relações de poder. $\mathrm{O}$ controle sobre o território e sobre recursos naturais comuns passa da comunidade ao consórcio empreendedor, sendo que este conta com o aparato institucional do Estado para fazer valer o seu direito de remover as famílias atingidas a despeito de suas vontades e de sua concordância. Ações de resistência são facilmente criminalizadas (ROCHA, 2013). 
Tomamos, aqui, a noção de "meios de vida", de Antônio Cândido (2010). São meios que se ligam à vida social, refletem formas de organização e de ajuste ao meio. O autor retoma a história, as relações socioeconômicas e as condições de vida do caipira tradicional. A ênfase recai sobre a obtenção dos meios de vida, aspecto considerado um tema sociológico e um problema social. Movendo-se entre as perspectivas da antropologia e da sociologia e renunciando à tarefa de estudar a "comunidade", opta por esses atores que representam a vida rústica do interior paulista, sem ignorar os demais aspectos da vida do município, recorrendo, para tanto, a fontes documentais e à história.

A categoria serve para pensarmos acerca do significado da megaobra (UHE Foz de Chapecó) nas vidas das comunidades ribeirinhas direta e indiretamente atingidas. A desestruturação socioambiental causada, no caso dos profissionais da pesca, representou a supressão de seus meios de vida.

\section{JUSTIÇA AMBIENTAL}

Os atores que postulam a justiça ambiental mobilizam-se ante a depredação capitalista dos territórios, convertidos em recursos para a produção de commodities em cenários neodesenvolvimentistas. Da mobilização nascem as redes de lutas ambientais, que têm como suporte a legislação de proteção ao meio ambiente, a inteligência coletiva e a criatividade institucional (BERGER, 2012). Em alguns países a legislação ambiental é mais protetiva, em outros é menos consistente, com diferentes níveis de institucionalização e de flexibilização.

Zhouri e Oliveira (2007, p. 120) descrevem uma tendência ao arrefecimento da legislação ambiental, à simplificação de procedimentos sob a justificativa de viabilizar o "desenvolvimento" no tempo desejado pelo empreendedor, de favorecer os grandes projetos ante as travas imposta pelo direito, especialmente o direito ambiental. A este fenômeno as autoras chamam "paradigma da adequação". A consequência é o estabelecimento de conflitos socioambientais que opõem, de um lado, os grupos econômicos (poderosos) e de outro as populações atingidas, as quais normalmente contam com parcos recursos (linguísticos, jurídicos, econômicos), em relações assimétricas e injustas. Nas palavras das autoras:

No "paradigma da adequação", a obra assume lugar central, apresentando-se de forma inquestionável e inexorável. Nesta concepção, o ambiente é percebido como externalidade, paisagem que deve ser modificada e adaptada aos objetivos do projeto técnico. Nesse processo, arranjos e ajustes tecnológicos dados por medidas mitigadoras e compensatórias cumprem a função de adequação (ZHOURI; OLIVEIRA, 2007, p. 122).

O que está em jogo é a distribuição social desigual dos riscos oriundos de atividades econômicas, notadamente industriais (aqui compreendido o 
agronegócio), que tendem a afetar de modo mais direto e em maior proporção às populações vulneráveis. Elementos como classe, etnia e gênero fazem parte da equação que expõe pobres, negros, indígenas e mulheres a fatores de risco de agravo a sua saúde, segurança e autonomia e convertem territórios em lócus de conflitos socioambientais.

Confrontados com a expertise dos agendes do desenvolvimento (Estados, capital privado, consórcios, parcerias público-privadas empresas transnacionais), que configuram o "neodesenvolvimentismo" latino-americado (LAMOSO, 2012), esses atores forjam estratégias de reação em defesa de seus territórios e dos meios de vida. A atuação em rede permite somar experiências, compartilhar desafios e construir-se na luta, exercitando a solidariedade e a democracia.

A luta é travada contra a exploração e a privatização dos bens comuns (água, terra, biodiversidade), o extrativismo e mercantilização da natureza para a produção de commodities (BERGER, 2012). No caso em estudo, trata-se da privatização dos recursos hídricos, transformados em insumo na produção hidroenergética, no que Vainer (2008) nominou "hidronegócio".

À semelhança do que ocorreu com o cercamento dos campos na Inglaterra da revolução industrial (Thompson, 1998), investidores capitalistas do setor energético tomam posse de cursos d'água, cercando-os para a produção hidráulica de eletricidade em empreendimentos de diferentes portes. Há grandes usinas hidrelétricas, que mobilizam vultosos capitais e produzem grandes contingentes de pessoas deslocadas, e pequenas centrais hidrelétricas, que demandam menos capital, ocupam porções menores de territórios, mas que, devido ao grande número, produzem impactos socioambientais significativos.

Conflitos se expandem, ganham corpo a partir da autocompreensão das vítimas do desenvolvimento. Em geral, trata-se de indígenas, agricultores, pescadores, ribeirinhos e outras comunidades tradicionais que vivem na dependência do rio. Suprimir o acesso ao recurso hídrico significa restringir-lhes os meios de vida e comprometer o seu sustento. Também restam comprometidas as características culturais das comunidades, seja pela perda do território, da profissão ou dos vínculos vicinais.

Sofrem especialmente as comunidades tradicionais que praticam a posse/propriedade comum dos territórios, uma vez que ocorrem a apropriação e privatização dos bens comuns. As fontes de sustento (terra, água, floresta) deixam de estar ao alcance das populações atingidas pelas barragens.

Há, também, a injusta distribuição da contaminação e da destruição dos bens comuns. No caso estudado, a eutrofização da água do rio Uruguai, após a formação do lago da barragem, assim como a redução drástica da vasão do rio à jusante prejudicaram sobremaneira os pescadores e ribeirinhos. Já não é possível fazer daquela água os usos que tradicionalmente se faziam (navegar, pescar, usufruir do lazer). 


\section{A COLÔNIA DE PESCADORES Z-35 APÓS A BARRAGEM}

Em entrevista realizada em fevereiro de 2019 na sede da colônia Z-35, o então presidente relata que antes da instalação da UHE Foz do Chapecó a colônia contava com cerca de 500 pescadores profissionais. Atualmente esse número não chega a 350. Muitos pescadores "abandonaram a carteira", isto é, deixaram a profissão. Alguns são moradores urbanos, mas a maioria é ribeirinho e planta milho, mandioca, cria porcos e galinhas para sobreviver. Não há empregos na cidade:

Os que deixaram a pesca estão em frigoríficos [em outros municípios], ou na agricultura, ou foram embora. (Presidente da colônia Z-35).

As entrevistas seguiram roteiro semiestruturado contendo questões abertas. Foram entrevistados dezoito pescadores, todos do sexo masculino, com idades que variam entre 31 e 61 anos.

Caracterização dos entrevistados

\begin{tabular}{|l|l|l|}
\hline Identificação & Idade & Tempo na pesca/Como começou a pescar \\
\hline (pescador 1) & 44 & 18 anos de carteira, mas sempre pescou com o pai. \\
\hline (pescador 2) & 58 & $\begin{array}{l}15 \text { anos de carteira, mas com 18 anos já pescava e trabalhava na agri- } \\
\text { cultura. }\end{array}$ \\
\hline (pescador 3) & 40 & 16 anos de carteira, mas sempre pescou; pai e mãe eram pescadores. \\
\hline (pescador 4) & 39 & 10 anos de carteira, mas começou a pescar com 5 ou 6 anos com o pai. \\
\hline (pescador 5) & 51 & $\begin{array}{l}12 \text { anos de carteira; o pai era pescador: "Na verdade eu não faço outra } \\
\text { coisa, desde criança eu sempre pesquei”. }\end{array}$ \\
\hline (pescador 6) & 53 & 20 anos de carteira, mas sempre pescou. Pai e mãe eram pescadores. \\
\hline (pescador 7) & 37 & 20 anos de carteira. Filho de pai e mãe pescadores. \\
\hline (pescador 8) & 44 & 16 anos de carteira. A mãe era pescadora. \\
\hline (pescador 9) & 54 & 15 anos de carteira. O pai era pescador. \\
\hline (pescador 10) & 51 & $\begin{array}{l}20 \text { anos de carteira. Pai e mãe pescadores: "O pai e a mãe criaram } 12 \\
\text { filhos só da pesca”. }\end{array}$ \\
\hline (pescador 11) & 31 & 8 anos de carteira. O pai era pescador. \\
\hline (pescador 12) & 42 & 11 anos de carteira. "Pescava desde piá com o pai”. \\
\hline (pescador 13) & 42 & 8 anos de carteira. O pai era pescador. \\
\hline (pescador 14) & 59 & 18 anos de carteira. O pai era pescador. \\
\hline (pescador 15) & 61 & Aposentado como pescador. \\
\hline (pescador 16) & 47 & 18 anos de carteira. O pai era balseiro. \\
\hline (pescador 17) & 40 & 18 anos de carteira. "Pesco desde piá". \\
\hline (pescador 18) & 42 & 19 anos de carteira. O pai era pescador. \\
\hline
\end{tabular}

Fonte: elaboração das autoras 
Aqueles que têm 60 anos de idade, ou mais, e 15 anos de bloco de notas de venda de pescado conseguem se aposentar. As mulheres têm que ter 55 anos, pelo menos. O entrevistado estima a existência de entre 10\% e 15\% de mulheres na atividade de pesca e processamento do pescado.

Muitos pescadores vêm encontrando dificuldades para receber o "defeso" (seguro defeso), pois no cadastro único do governo consta que receberam bolsa família, o que seria um impedimento.

Em alguns casos o seguro defeso é negado sob a alegação de que a pessoa comercializou milho e é proprietária de terra, o que descaracterizaria a condição de segurado especial como pescador. Em geral, quando entram com processos administrativos têm o benefício indeferido. Somente obtêm sucesso quando contratam advogado.

Todos os pescadores entrevistados ingressaram com ações na justiça contra a Foz do Chapecó Energia a fim de reclamar indenização por danos decorrentes da instalação da barragem. Algumas ações foram julgadas improcedentes nas comarcas e no Tribunal de Justiça de Santa Catarina, em grau de recurso. O TJ/SC não reconhece o nexo causal entre a diminuição do pescado e o barramento do rio Uruguai para produção hidroenergética (SANTA CATARINA. TRIBUNAL DE JUSTIÇA, 2018).

Os pontos de apoio à pesca que foram construídos pelo Consórcio Foz do Chapecó, que eram três, foram condenados pela defesa civil e estão abandonados. Um deles vem sendo ocupado por duas famílias de pescadores que não têm renda para pagar aluguel.

Os entrevistados contam que o rio já não é navegável. Outrora atingia 800 metros de largura e atualmente há lugares onde a largura não chega a dez metros. Há pequenos trechos em que ainda é possível passar com o barco. A água está contaminada por excesso de matéria orgânica que vem do lago da barragem.

À jusante do barramento os alevinos morrem por causa da oscilação do nível da água, que é controlada pela abertura das comportas. A promessa de instalar tranques-rede, que foi contemplada no Plano Básico Ambiental, não saiu do papel. Na opinião dos entrevistados, essa alternativa é inviável porque "não tem água para isso, está muito poluída”.

Relatam que antes da diminuição da vazão do rio pescavam com 300 metros de rede, e que atualmente necessitam lançar de dois a três mil metros de rede. Perdem muito material por causa dos mexilhões e pelas oscilações da vazão, que danificam as redes.

Antes [da barragem] pescava 40, 50 quilos de cascudo por dia, piava, dourado, bocudo, pati. Dava para viver da pesca. Tinha placa na beira da estrada e vendia para os restaurantes. Hoje a vigilância quer que abra frigorífico. É inviável, tem que abrir uma firma sem ter o produto para vender. (pescador 3). 
O rio está infestado de mexilhão dourado, que é exótico, é uma praga, menor que o marisco marítimo. Tem mato onde antes era o rio. Tem que puxar o caíco a pé. (pescador 4)

Antes da Foz, nove em cada dez pescadores pescavam a muque, sem motor, com poucos metros de rede. Pegavam dourado de cinco quilos. Agora o dourado não chega a pesar dois quilos e está fora da medida, se pegar leva multa. (pescador 3)

A multa consiste na obrigação de soltura de dois mil alevinos adquiridos pelo infrator.

Outra fonte de renda, além do pescado, eram os passeios com turistas. Levavam turistas passear no rio e pescar, ganhavam as diárias e vendiam os peixes. Faziam de três a quatro fretes por semana para pescadores amadores. Hoje, segundo relatam, não dá mais para navegar. Acabou o turismo em Pratas, tradicional balneário local.

Se hoje não está bom, não está bonito, é porque eles nos tiraram! (pescador 2)

Quando a rede vem vazia a gente pensa: o que é que vai fazer? Como vai viver? (pescador 1 )

Percebem uma alteração na temperatura da água devida à baixa profundidade e à formação de poços e relatam a ocorrência de uma infestação de pernilongos que os obriga a usar repelente para trabalhar.

Antes pegava peixe, não tinha crise, comia e vendia peixe, vivia bem. Depois virou em Sarandi, sumiu o bocudo, piava, cascudo amarelo. Os barracões, elefante branco, estão abandonados porque não tem peixe. Tem piranha e palomita. (pescador 9)

Afirmam que havia sido pactuado com o Consórcio Foz do Chapecó o recebimento da quantia de dez mil reais por pescador e de pontos de apoio à pesca, mas com o entendimento de que essa negociação poderia ser retomada se as condições para a pesca se tornassem adversas. No entanto, a Foz do Chapecó Energia não quer reabrir o diálogo.

Disseram que não ia secar o rio, de mil metros virou em 15. Dá para plantar feijão! (pescador 6)

Tinham acertado em ata com a Foz, estava o governo, que se diminuísse o peixe fariam outra reunião para acertar. Nunca mais apareceram. (pescador 6) 
Relatam que na perícia judicial realizada nos processos de indenização, os profissionais utilizam redes com malhas variadas $(1,2,3,4,5)$, e por esta razão capturam peixes pequenos. No entanto, o pescador tem que usar malha sete, no mínimo, ou é multado pela polícia ambiental. Em outras palavras, o resultado da perícia aponta a existência de peixes, mas estes não são adequados para a prática da pesca profissional.

Alegam, ademais, que a qualidade da água está ruim. Registram a presença de limo, que adere às redes, danificando-as. Em muitas ocasiões os peixes morrem nas redes e não podem ser aproveitados. Estão muito machucados porque tentam subir a corredeira e se chocam contra as pedras. Por isso morrem e apodrecem nas redes.

Mudou tudo. Aqui não tem mais nada bom. (pescador 15).

Onde era o rio, agora é mato (pescador 17).

Não tem mais jeito. O único culpado é essa barragem aí! No começo eles adoçam, ajudam a prefeitura, amaciam... (pescador 16)

Os caras do INSS têm raiva de pescador (pescador 3).

As ações conjuntas e coletivas dos atores são produtoras da identidade de atingido, afectado, vítima do desenvolvimento, dando lugar a um saber compartilhado, a formas de articular-se em rede e de relacionar-se com diferentes institucionalidades (oficiais e não oficiais) a fim de manter viva a luta por justiça.

Nas palavras de Berger (2012, p. 115)

As lutas constroem um sentido de justiça que desborda as instituições estatais e sua administração da "justiça", antepondo a ideia de igual dignidade e a prática da convergência de saberes, apropriando-se de um conceito que surge precisamente da criatividade estratégica das lutas: a justiça ambiental.

Decorrida uma década do fechamento das comportas e da formação do lago artificial, as condições de exercício da pesca profissional seguem obstaculizadas por uma série de fatores que envolvem as condições limnológicas e a ictiofauna prevalecente no novo ambiente.

Além deste fator, há o problema da falta de reconhecimento da condição de pescador pela Previdência Social, o que deixa muitos profissionais fora do "seguro defeso" (benefício previdenciário pago aos pescadores no período em que a pesca está proibida por razões ecológicas). Sem essa garantia, os profissionais veem-se obrigados a mudar de profissão a fim de buscar o sustento da família. 
Há as demandas judiciais propostas por pescadores atingidos negativamente pela Foz do Chapecó Energia e que postulam reparação do dano ambiental individual sofrido, algumas das quais já com decisões de primeiro e de segundo grau. Nas comarcas da região, algumas dessas ações não reconheceram nexo de causalidade entre os prejuízos sofridos pelos profissionais da pesca e as ações empreendidas pela empresa energética. Outras foram julgadas procedentes. No entanto, em grau de recurso, as ações apreciadas pelo Tribunal de Justiça de Santa Catarina foram julgadas improcedentes.

\section{CONSIDERAÇÕES FINAIS}

A instalação da UHE Foz do Chapecó foi um acontecimento que marcou a região e a alguns segmentos como um divisor de águas entre um "antes" e um "depois" da barragem. Antes havia comunidade; depois a comunidade deixou de existir ou não foi mais a mesma. Antes havia pescado e era possível viver da pesca artesanal; depois essa atividade tornou-se inviável. Antes a vida era boa, depois veio a incerteza ante a supressão dos meios de vida.

A teoria dos meios de vida tem a ver com o problema elementar da subsistência. Os meios de vida são um "fator dinâmico, tanto da sociabilidade, quanto da solidariedade que, em decorrência das necessidades humanas, se estabelece entre o homem e a natureza, unificados pelo trabalho consciente" (CÂNDIDO, 2010, p. 13-14).

Operam, neste caso, a lógica do encolhimento dos benefícios sociais do Estado e a ampliação da liberdade de atuação empresarial no contexto neoliberal. Ocorre o aviltamento de direitos dos trabalhadores e evidencia-se a desproteção das vítimas do desenvolvimento, condenadas a conviver com as consequências nefastas do empreendimento desenvolvimentista. Planos e programas ambientais do empreendedor, que visam transformar o pescador em aquicultor, não foram implementados.

Os pescadores entrevistados tentam adaptar-se ao novo ambiente do rio, ante a impossibilidade de começar uma nova profissão. Para trocar de profissão teriam de migrar para um centro urbano maior, para procurar emprego, o que veem como algo incerto. As ações judiciais não alcançaram o resultado desejado, até o momento. A Foz do Chapecó Energia não se responsabiliza pelos danos causados à pesca artesanal no trecho à jusante da barragem.

Alternativas encontradas são os trabalhos esporádicos desenvolvidos no município de São Carlos e o cultivo de pequenas roças. No entanto, essas atividades podem descaracterizar a condição de pescador profissional, comprometendo o recebimento do seguro defeso e a aposentadoria. Nas palavras de um entrevistado, "só sei fazer isso [pescar] e é muito tarde para começar outro serviço" (pescador 9). Persistem na profissão por falta de opção. 


\section{NOTAS}

1 Este trabalho é resultado de pesquisa financiada pelo Conselho Nacional de Desenvolvimento Científico e Tecnológico - CNPQ.

2 São exemplos a deflorestação da Mata Atlântica e a erosão de espécies.

\section{REFERENCIAS}

ACSELRAD, Henri; HERCULANO, Selene; PÁDUA, José Augusto (Org.) Justiça Ambiental e Cidadania. Rio de Janeiro: Relume Dumará, 2004.

BARDIN, L. Análise de Conteúdo. Lisboa, Portugal; Edições 70, LDA, 2009.

BARON, Sadi. UHE Foz do Chapecó: estratégias, conflitos e o desenvolvimento regional. 2012. Dissertação (Mestrado em Dinâmicas Regionais e Políticas Sociais) - Unochapecó, Chapecó, 2012.

BERGER, Mauricio. Justicia ambiental en América Latina. Inteligencia colectiva y creatividad institucional contra la desposesión de derechos. e-cadernos Centro de Estudos Sociais. Coimbra, n. 17, 2012: 112-135

BERGER, Mauricio; CARRIZO, Cecília. Aportes de una sociología de los problemas públicos a la justicia ambiental en América Latina. Revista Colombiana de Sociología. Bogotá-Colômbia. Vol. 39, nº 2, Dic. 2016, p. 115-134.

BERMANN, Célio. Impasses e controvérsias da hidreletricidade. Estudos Avançados 21 (59), 2007, p. 139-153.

BRASIL. Lei n. 9.433/ 1997 - Política Nacional de Recursos Hídricos. Disponível em: http://www.planalto.gov.br/ccivil_03/LEIS/L9433.htm. Acesso em 14 de set 2019.

CÂNDIDO, Antônio. Os parceiros do rio Bonito. Estudo sobre o caipira paulista e a transformação dos seus meios de vida. $11^{a}$ edição. Rio de Janeiro: Sobre Ouro Azul, 2010 .

DAL MAGRO, Márcia Luiza; RENK, Arlene; FRANCO, Gilza Maria de Souza. Impactos socioambientais da implantação da hidrelétrica Foz do Chapecó. Chapecó: Argos, 2015.

EMPRESA DE PESQUISA ENERGÉTICA - EPE. Plano decenal de expansão de energia.

ENGENHARIA E CONSULTORIA SOCIOAMBIENTAL - ECSA. Aproveitamento Hidrelétrico Foz do Chapecó - Plano Básico Ambiental - PBA. Florianópolis, 2003.

FRASER, Nancy. Escalas de justicia. Barcelona: Herder, 2008.

LAMOSO, Lisandra Pereira. "Neodesenvolvimentismo" brasileiro: implicações para a integração regional no âmbito do Mercosul. Sociedade \& Natureza. Uberlândia (MG), ano 24 , n. 3, set/dez. 2012, 391-404. 
POUPAERT, Jean et al.. A pesquisa qualitativa. Enfoques epistemológicos e metodológicos. Petrópolis: Vozes, 2008.

RENK, Arlene; WINCKLER, Silvana. De atingidos a vítimas do desenvolvimento: um estudo junto à população atingida direta ou indiretamente pela UHE Foz do Chapecó na região oeste de Santa Catarina. Revista Direito Ambiental e sociedade, Caxias do Sul (RS), v. 7, n. 2, 2017, p. 197-211.

RIBEIRO, Gustavo Lins. Poder, redes e ideologia no campo do desenvolvimento. Novos Estudos (CEBRAP), São Paulo, n. 80, Março/2008, 109-125.

ROCHA, Humberto José da. A criminalização dos movimentos sociais ante a instalação de uma hidrelétrica no rio Uruguai (Brasil): uma discussão entre o legal e o legítimo. Idéias, Campinas (SP), n. 8, nova série, $1^{\circ}$ semestre (2014), p. 191-214.

THOMPSON, Edward Palmer. Costumes em comum. Tradução de Rosaura Eichemberg. São Paulo: Companhia das Letras, 1998.

ZHOURI, Andrea; OLIVEIRA, Raquel. Desenvolvimento, Conflitos Sociais e Violência no Brasil: o caso das usinas hidrelétricas. Campinas: Grupo de Estudo em Temáticas Ambientais, 2007.

Submetido: $30 / 03 / 2020$

Aceito: $15 / 04 / 2020$ 


\title{
A SUPRESSÃO DOS MEIOS DE VIDA DOS PESCADORES PROFISSIONAIS IMPACTADOS PELA USINA HIDRELÉTRICA FOZ DO CHAPECÓ
}

\begin{abstract}
Resumo
O texto tem como objetivo analisar impactos socioambientais da instalação da Usina Hidrelétrica Foz do Chapecó no rio Uruguai, região sul do Brasil, na pesca artesanal e as alterações produzidas nos meios de vida dos profissionais da Colônias de Pescadores Z 35. Na Colônia, verificou-se que houve redução de um terço no número de pescadores após o enchimento do lago. Metodologicamente, a pesquisa caracteriza-se como qualitativa. Compreende revisão de literatura, levantamento documental de diagnósticos, planos e programas ambientais e entrevistas com pescadores afetados. Adota-se como estratégia a pesquisa narrativa. Constatamos que, ante a inviabilidade da atividade, os pescadores recorrem à previdência social e ao empreendedor a fim de obter os meios de vida na forma de seguro defeso, aposentadoria e indenização. Concluímos que operam, neste caso, a lógica do encolhimento dos benefícios sociais do Estado e a liberdade de atuação empresarial no contexto neoliberal. Evidenciamos a desproteção das vítimas do desenvolvimento, condenadas a conviver com as consequências nefastas do empreendimento desenvolvimentista. Planos e programas ambientais do empreendedor, que visam transformar o pescador em aquicultor, não foram implementados.
\end{abstract}

Palavras-chave: Barragem. Conflitos socioambientais. Desenvolvimentismo. Megaprojetos. 


\title{
THE SUPPRESSION OF THE LIVELIHOODS OF PROFESSIONAL FISHERMEN IMPACTED BY THE FOZ DO CHAPECÓ HYDROELECTRIC POWER PLANT
}

\begin{abstract}
The text aims to analyze the social and environmental impacts of the installation of the Foz do Chapecó Hydroelectric Power Plant on the Uruguay River, southern region of Brazil, on artisanal fishing and the changes produced in the livelihoods of the Z 35 Fishermen's Colony professionals. In the Colony, there was a one-third reduction in the number of fishermen after the lake was filled. Methodologically, the research is characterized as qualitative. It includes a literature review, a documental survey of diagnoses, environmental plans and programs, and interviews with affected fishermen. Narrative research is adopted as the strategy. We found that in the face of the unfeasibility of the activity, fishermen resort to social security and entrepreneurship in order to obtain the means of life in the form of closed insurance, retirement and indemnity. We conclude that they operate, in this case, the logic of the shrinking of social benefits of the State and the freedom of entrepreneurial action in the neoliberal context. We highlight the lack of protection for the victims of development, condemned to live with the harmful consequences of developmental enterprise. Environmental plans and programs of the entrepreneur, which aim at transforming the fisherman into a fish farmer, have not been implemented.
\end{abstract}

Keywords: Dam. Socio-environmental conflicts. Developmentalism. Megaprojects. 